\section{Amlyn L. Evans}

Received: 7 June 2006

Accepted in revised form: 14 June 2006

Published online: 11 August 2006

\title{
Patient confidentiality issues and accuracy of medical images used in publications
}

I read with interest a recent article about a case of spontaneous intracranial hypotension in this journal by Trappolini et al. [1]. I am appalled by the lack of care in the preparation of the figures illustrating the case. Firstly, and most importantly, there has been no effort in maintaining patient confidentiality - the patient's name and date of birth are clearly visible on the images. Secondly, the image quality is poor distorted, slightly blurred images of radiological investigations in my opinion should not be acceptable for print publication. Thirdly, Figure 1 does not correlate well with the authors' interpretation - the figure legend states that the label 'b' corresponds to a 'subdural fluid collection (aka hygroma)'; the arrow in fact does not represent a hygroma, merely the contrast-enhanced left transverse venous sinus.

Perhaps it would be prudent for Authors to enrol the help of their local radiology department both in the preparation of images and in the interpretation in the figure legends. It is a simple matter in these days of radiological PACS systems and worksta- tions to export high-quality, anonymous, in-focus images. Images photographed from film would be acceptable from older radiological studies where electronic images were not available. These images, if they are the only option available, should be professionally prepared and not by, as I presume the Authors in this study have used, a hand-held digital camera.

Patient confidentiality is a serious issue [2]. Some journals require written informed consent from patients before accepting images for publication, nevertheless it should be a physician's duty to protect that individual's identity where possible. All possible efforts should be made by researchers, authors and journal editors to protect this confidentiality. There are also guidelines issued from the European Parliament on data confidentiality, which should be adhered to.

A.L. Evans (ه) Department of Neuroradiology, Royal Hallamshire Hospital, Glossop Road, Sheffield S10 2JF, UK e-mail:amlyn.evans@sth.nhs.uk

\section{References}

1. Trappolini M, Clarice A, Scorza A, Angrisani L, Trappolini F, Rocchietti March M, Proietta M (2006) A case of spontaneous intracranial hypotension with typical magnetic resonance images. J Headache Pain 7:44-46
2. Soteriou T, Hek G, Gray S (2005) Patient confidentiality, clinical data and NHS research - a researcher's guide. Nurse Res 13:19-26 